\title{
Development Research of Xinjiang Uygur Autonomous Region Sports Tourism Resources
}

\author{
Li Xuezhi \\ School of Business, Linyi University, Shandong Province 2760005, China \\ lixuezhisd@126.com
}

\begin{abstract}
This paper is based on strengths and weakness of Sports tourism resources in Xinjiang Uygur Autonomous Region; it mainly analyzed the following problems such as under-development of sport. Tourism resources in Xinjiang, lack of professional talents, backward of hardware facilities, lack of financial supports and so on. For promoting the development of sports tourism in Xinjiang Uygur Autonomous Region, this paper proposes these solutions, use unique condition to carry out the special item, the government should play the leading role, improve the traffic facilities, personal training of sports tour special field.

Index Terms - Sports Tourism Resources, Develop Research, Xinjiang Uygur Autonomous Region

In recent years, the sports tourism industry has developed rapidly in many countries such as Britain, the United States, Germany, Italy, Japan and other countries. China's sports tourism began to develop since the mid-1990s, time of development is relatively short and sports tourism resources has not been fully and reasonable exploited in many areas, especially in xinjiang Uygur Autonomous Region.
\end{abstract}

\section{The Advantage of Xinjiang Uygur Autonomous Region Sports Tourism Resources}

Sports tourism resources include both natural environment fit for sports and activities, but also include sports culture, sports games, sports events which tourists participation in and have the ornamental and fitness value. The construction or service facilities for travel or sports tourism are also included.

Xinjiang Uygur Autonomous Region is located in the middle of Eurasian, it lays on the west of China, it is the largest Province in China which has the longest border and most border neighboring provinces and regions. Xinjiang Uygur Autonomous Region has extremely rich tourism resources, graceful natural landscapes, historical relics, and unique ethnic customs, it has been hailed as the backup bases of tourism resources in China.

There are four categories sports tourism resources in Xinjiang Uygur Autonomous Region if roughly classified, they are natural landscape category, cultural landscape category, folk category and events category. Natural landscape categories include mountain type, valley type, hot spring type, desert types, grassland type, forest type, glacier type etc. Cultural landscape categories include Venue types, which having scientific or historical or artistic value, and Cultural relics and historic sites such as rock paintings, thousand-buddha grottoes, ancient ruins groups, ancient tombs groups and so on .Folk category include colorful and plenty of ethnic culture activities with strong national and local characteristics which can arouse the curiosity of tourists and festival types. Events category include Central Tower Rally, International Hot Air Balloon Festival, Skydiving championship in Asia ,the International Boxing Tournament, Desert Hiking Adventure Race, Central Sailimu Lake bike race etc.

\section{A. Snow, rivers, desert and mountains can be used to carry out adventure programs.}

Xinjiang Uygur Autonomous Region is one of the regions with the richest ice and snow tourism resources due to its high latitude and cold climate. Especially North Xinjiang, the long snow days and high quality thickness snow are wonderful natural geographical advantages of exploring winter ice and snow tourism. For example, snowing days of south Altai area can be as long as 110 days, north to Tianshan and Yili areas around 6 month; snow thickness of north Tianshan and Yili river valley is above $60 \mathrm{~cm}$.

The supply of Xinjiang river water source comes mainly from the mountain precipitation, the snow of the three big mountains and glacier melt water. Although Xinjiang Uygur Autonomous Region is far away from the ocean, there are many lakes and rivers. One of the longest continental river in China, the Tarim river, has been attracted a lot of adventure travelers home and abroad since ancient times.

The desert area in Xinjiang Uygur Autonomous Region is 43.04 square kilometers, and this is nearly $60 \%$ of the total desert area of China. There are endless sand dunes, magic singing sand, the devil windy city and yardang landform. It is an ideal venue for desert adventure, desert automobile, motorcycle and bicycle rally.

The terrain of Xinjiang Uygur Autonomous Region is very complicated, and mountains are diversified. There are hundreds of perennially snow covered mountains. These mountains are located in the Altai Mountains, Mount Tianshan and Pamir karakoram. When you want to climb the Everest along the Northern slope, you can find the wonderful scenery if you do mountain climbing and expedition start from Xinjiang.

Four of the world's 14 highest mountains are in xinjiang Uygur Autonomous Region, among them, Godwin Austin --8611 meters above sea level Is the world's second 
highest peak. There are 12 mountains 7000 or 8000 meters above sea level in xinjiang Uygur Autonomous Region, also There are hundreds of snow mountains. All of them are attract a large number of mountaineering adventure tourists.

\section{B. Xinjiang Uygur Autonomous Region is famous for different types of traditional sports items.}

Xinjiang Uygur Autonomous Region is a multi-ethnic region, including 13 main nations, in the history of development, each nation created its own traditional sports activities with rich ethnic characteristics, providing valuable resources for the development of sports tourism, such as the wrestling of jipladi family; Kazak sheep, chasing girls; Kirgiz Pegasus pickup silver. Among them, horse racing, wrestling, archery, national swing, Wushu has become official events of national minority sport competitions.

Xinjiang Uygur Autonomous Region has various type of festivals, organizes festivals can attract tourists, adds luster of Xinjiang Uygur Autonomous Region tourism program. Especially colorful Manchu ethnic dance and sports, visitors can not only see a lot of performances, but also can personally participate in competitions and entertainment, the body and mind dissolved into a sea of joy.

\section{Hot spring provides good conditions to have leisure or recuperate.}

Xinjiang Uygur Autonomous Region is famous for its hot spring resources, such as Bortala Hot Spring, Wucaiwan Desert Hot Sping, Alashan Hot spring etc. Hot Spring in Xinjiang Uygur Autonomous Region is famous for its soft water quality, the water is rich in carbonates, sulphur, phosphorus, boron, bromine and iodine and other trace elements, it is good place for leisure and recuperate.

D. The forest resources of Xinjiang Uygur Autonomous Region is available to develop sports such as hunting.

Many scenic spots and forest landscape in xinjiang Uygur Autonomous Region are inseparable. Xinjiang Uygur Autonomous Region forest landscape includes all types of forest parks and nature reserves, now Xinjiang Uygur Autonomous Region has more than 50 forest park at all levels, including 13 the national level ones; 26 natural reserve areas at all levels, including 6 national 6; 15 hunting grounds, of which 11 international ones.

\section{The Disadvantage of Xinjiang Uygur Autonomous Region Sports Tourism Resources.}

\section{A. Xinjiang Uygur Autonomous Region Tourism is not fully developed.}

As a world class tourism destination, the development of sports tourism in Xinjiang Uygur Autonomous Region mainly rely on its unique natural environment, the sports tourism project quality is not high now and not productive enough, at the low level of development, did not reflect the overall strength and comprehensive functions of regional sports tourism resources, greatly reduces the development degree of sports tourism resources.
Although some areas carried out the minority traditional sports performance, but the scale is small, site design is simple, performance technology is poor, can not attract enough tourists. In addition, less projects is designed to let tourists participated especially for different age groups, ethnic sports tourism projects need to be further mining or exploited.

\section{B. Xinjiang Uygur Autonomous Region lacks the professional talents of developing sports tourism.}

Sports tourism requires inter-disciplinary talent, first of all, sports tourism managers should be familiar with the operation of the tourism business, grasp the tourism market, at the same time, understanding the characteristics of sport projects, knows how to combine sports with tourism; secondly, sports tourism project requires participants to master corresponding motion technology and skills, which requires professional and specific personnel to organize and train the participants. Now there is a very big talent gap in Xinjiang sports tourism, the sports tourism resources and reserve force is obviously insufficient.

But at present, the human resources quantity and quality can not meet the development. In xinjiang Uygur Autonomous Region sports tourism. The number of existing sports tourism enterprise employees is small, and the overall quality is not high. These factors, such as sports tourism experience severe shortage, poor management, quality of service is not well, affecting the development of sports tourism market.

\section{The development of sports tourism in Xinjiang Uygur Autonomous Region lacks financial support and material backup.}

Xinjiang Uygur Autonomous Region is at a fairly low level of economical development and not enough financial support. Although Xinjiang Uygur Autonomous Region has given priority to tourism in planning, the financial investment is very limited now. Due to severe financial insufficient in development promotion, education training and infrastructure and low level income of common citizen, directly causes the insufficient demanding of sport tourism market.

A number of Xinjiang Uygur Autonomous Region sports tourism area, are far from the city center, tourism infrastructure such as hotels, restaurants, toilet are of small scale, low level and limited quantity, sports tourism activities venues are small, activity sites are with very simple design, facilities relatively low-end, sports tourism facilities can not fully meet the needs of its development, many development projects can not be fully developed due to lack of facilities.

\section{Under-developed traffic system}

Xinjiang Uygur Autonomous Region is of vast expanse, the scenic (points) are more dispersed, the distance between adjacent areas are hundreds of kilometers, even thousands of kilometers. Time spent on road takes up half of the travel time in total, leads to the severe problem of 
time traveling on road much more than enjoying. Xinjiang Uygur Autonomous Region expressway, highway, railway has not yet formed a smooth traffic network, and road and rail travel time is long, the route is relatively simple; travel costs are relatively high by plane; and many tourist area has no airport, the traffic problem is one of the biggest obstacles to the development of sport tourism in Xinjiang.

\section{E. Sports and tourism industry issues}

Although aware of the potential business opportunities of Xinjiang Uygur Autonomous Region sports tourism market, but inexperience of sports tourism resources development, management and other aspects still are seriously due to the lack of "sports" background. which affects the further development of sports tourism to a certain extent. Displays in: First, the sports industry and tourism industry dependency of different departments and the integration of tourism industry and sports industry is the inevitable trend and requirements of industrial development, but in fact there are seldom. Second, the government-led tourism management system has not set up, so lack of government effective guide for the development of sports tourism projects. Third, the goal and direction of sports tourism development are not clear, key support of the tourism development is deficiency in Xinjiang Uygur Autonomous Region .

\section{F. Infrastructure construction for sports tourism is poor}

Because numerous sports tourism resources in Xinjiang Uygur Autonomous Region are far from the city center, scale of tourism infrastructure such as hotels, restaurants, toilets and other buildings is small and the quantity is limited. Sports tourism activity venue is also small and design simple, equipment or apparatuses single species, so those facilities can not meet the needs of sports tourism development and many development projects can not be carried out.

\section{Solutions of Exploring Sport Tourism Resources in Xinjiang Uygur Autonomous Region}

\section{A. Develop typical, high-quality tourism projects.}

Feature is the soul and life of the tourism industry, uniqueness and strength are the success of tourism development.

\section{1) Take advantage of the unique natural resources, carry out characteristic projects.}

To carry out the exploration projects. Using Xinjiang mountains, rivers, deserts, and forests and other natural resources, to carry out mountaineering and rock climbing, mountain hiking, river rafting from driving cross-country, forest orientation adventure, paragliders and a series of stimulating recreational sports tourism projects.

To carry out leisure and healthcare projects. Using in lakes, beaches and other resources in xinjiang, to develop beach volleyball, swimming, boating, fishing and other recreational projects; And resources such as hot springs, desert in Xinjiang are unique, it is practical to carry out health care tourism projects such ad spa, sunbathing and sand therapy.

Sports competition projects. By taking advantage of resources such as desert, gobi, to combine with the reality of Xinjiang sports advantageous projects, to carry out domestic and international motorcycle grand prix and car rally every year; And use xinjiang Uygur Autonomous Region basketball league as the breakthrough point, to create a well-known annual event through out the country, start vast sports tourism market.

2) To carry out snow and ice sport tourism using snow and ice resources.

As the the world's most popular winter ice and snow sports tourism project, ice and snow sport has attracted many tourist lovers with its participation, fun, stimulating character. On the project for the development of winter ice and snow sports tourism, in addition to conducting speed skating, skiing, ice football, track type $S$ sleigh, snow sledge, snow, snowball fights and other entertainment projects, the tourists are able to experience the charm of the snow from all aspects. Such as government departments intensify winter ice and snow sports tourism development and promotion, can create new economic growth point of off-season tourism in xinjiang Uygur Autonomous Region.

3) Take Advantage of the characteristics of multi-ethnic, to carry out national sports tourism

Make full use of minority national sports in the development of tourism, such as big-game hunting, tug-of-war, wrestling, horse racing, to develop ethnical sports tourism projects and attracting tourists.

B. Take the government's leading role into play in the development of sports tourism in Xinjiang Uygur Autonomous Region.

Xinjiang Uygur Autonomous Region government should guide people to emancipate minds, be fully aware of the significance of developing tourism, deepening the reform of xinjiang Uygur Autonomous Region tourism industry system, pay attention to tourism policy, laws and regulations system construction, rectify the market order, strengthen management, increase the publicity of tourism, and reasonable planning, increase the depth of development. Social stability in the Xinjiang area, the personal safety is the most concern problem of tourists, so social stability in xinjiang Uygur Autonomous Region is important.

The government should have practical measures to ensure the safety of tourists and the correct guidance of public opinion. Tianshan Wulin competition successfully attracted many of the media and public attention, Xinjiang Uygur Autonomous Region can learn from similar event marketing means to promote the ethnic sports tourism

\section{Improve the traffic facilities}

In recent years, traffic building is a big leap in xinjiang Uygur Autonomous Region, Xinjiang highway has become the subject of traffic, the mileage of highway network up to 
$3400 \mathrm{~km} 2$, leading to nearly 30 domestic cities, more than a dozen countries and regions; A total length of railway is over $2500 \mathrm{~km} 2$ and has opened to many domestic cities such as Beijing, Shanghai, Chengdu, Zhengzhou, Xi'an etc. Civil aviation, there are 21 airport, 61 routes at home and abroad 2,1 Boeing series of long-range aircraft in xinjiang Uygur Autonomous Region.

Although Xinjiang' $s$ traffic construction has made great progress, but the traffic capacity shortage is still a prominent problem, especially during the tourism golden week and golden tourist season, traffic facilities shortage is still quite obvious, therefore the traffic facilities need to be improved to enlarge the accessibility of tourists.

\section{Develop a variety of financing channels}

As economically underdeveloped provinces in the west, development of xinjiang Uygur Autonomous Region sports tourism needs to explore a variety of financing channels to strengthen the investment promotion and capital introduction and a variety of favoring policies and managing methods to promote tourism development. It is very helpful to develop Xinjiang's sport tourism to encourage individuals, collective, enterprises, and whole nation to invest in the exploration of Xinjiang Uygur Autonomous Region sport tourism resources.

\section{E. Cultivating sports tourism talents}

Unlike regular travel, Sports tourism is more difficult, more demanding, more specialized in operating procedures. Sport tourism employees such as outreaching people, adjustable, guide, driver, etc., have to be equipped with sports tourism related knowledge, experience and skills. So develop and be equipped with a rich knowledge, diligent team with strong sense of security, familiar with customs and strictly implementing national policy, who are interested in sports tourism is very important. Also tourism colleges should be found and increase tourism professional trainings to cultivate related talents or such talents should be introduced from home and abroad.

\section{F. Pay attention to travel safety}

Due to the particularity of sports tourism, the tourism environment and related conditions different from the conventional tourism, so the implementation of control during operation is complex and difficult than conventional tourism, at the same time, the risk is greater than conventional tourism.

For example sports tourism must be particularly aware of Safety scenic line design, in the design all the possible risk that people can expect should be avoided, to put the risk in the lowest level.

In addition to the odd and diversity characteristic of sports tourism mode, the supporting services in every aspect of tourism can not completely perfect, there must be many unpredictable factors and disadvantageous factors, which requires the lines in the organization should control each aspect, ready for all kinds of emergency measures and means, checks and analysis all the details of the journey, to ensure tourists get satisfactory service.

Although tourism is an immaterial production branch, it has a strong association driven features. To develop the national sports tourism not only can drive the national sports equipment industry, national sports clothing industry, but also to promote the development of the transport industry, business services, telecommunications industry, financial and other related industries directly or indirectly, consumer spending on sports, fitness, culture and entertainment also increased considerably. So as to promote the national economy, will continue to change people's consumption concept, consumption habits and consumption structure, change of social demand structure, and ultimately to make social resource reorganization, resulting in the optimization of the industrial structure.

Most ethnic minority areas are underdeveloped areas and poverty area, but also they are the national sports and tourism resources enrichment area, therefore, give full play to the advantages and characteristics of poverty areas, develop distinctive high-grade national sports tourism products can eliminate poverty in poor ethnic minority areas and help the poor become rich.

\section{References}

[1] Hanjie, Handing, Research and study of skiing tourism in China, Econ omic Geography, 2001 (4) 500-503.

[2] Wang Tianjun, Prospect and Countermeasures of developing national s port tourism, Guangzhou sport college journal, 2000, (2) 5-9

[3] [EB/OL].Baidu Wikipedia, Bortala Mongol Autonomous area, http://b aike.baidu.com/view/118938.htm\#6, (2010-05-05)

[4] [EB/OL]. http://news.tom.com, (2009-12-10)Chinese News Net

[5] Tu Yuchun, Xinjiang Tourism: Advantages and industrial confusions, Southwest national university journal, 2005, (4) 132-134

[6] Liu Dong, Development of Xinjiang Sport Tourism Resources. Journal of Sports , Adult Education, 2004, (8) 